\title{
MULTICONICAL TRANSVERSE PATTERNS OF MONOLITHIC MINI-CAVITY OPTICAL PARAMETRIC OSCILLATOR
}

\author{
M. Peckus ${ }^{\text {a }}$, K. Staliūnas ${ }^{\text {b }}$, M. Saffman ${ }^{\text {c }}$, G. Šlekys ${ }^{\text {d }}$, V. Sirutkaitis ${ }^{\text {a }}$, \\ V. Smilgevičius ${ }^{\mathrm{a}}$, and R. Grigonis ${ }^{\mathrm{a}}$ \\ ${ }^{a}$ Vilnius University Laser Research Centre, Saulètekio 10, LT-10223 Vilnius, Lithuania \\ ${ }^{\mathrm{b}}$ ICREA, Departament de Fisica i Enginyeria Nuclear, Universitat Politecnica de Catalunya, Colom 11, E-08222 Terrassa, \\ Barcelona, Spain \\ ${ }^{\mathrm{c}}$ Department of Physics, 1150 University Avenue, University of Wisconsin, Madison, Wisconsin, 53706 USA \\ d Altechna, Konstitucijos 23A, LT-08105 Vilnius, Lithuania
}

Received 31 March 2005

\begin{abstract}
We investigate theoretically and show experimentally multiconical transverse patterns of degenerate optical parametric oscillators in monolithic mini-cavities. We show the tunability of the conical emission angle, the switching between different resonant cones, and simultaneous emission on different cones, depending on the pump angle as well as on the length of the resonator.
\end{abstract}

Keywords: multiconical transverse patterns, monolithic mini-cavity, optical parametric oscillators, nonlinear optics

PACS: 42.65.Yj, 42.65.Sf, 47.54.+r

\section{Introduction}

Transverse pattern formation in broad aperture lasers and in other nonlinear optical resonators like photorefractive oscillators and optical parametric oscillators (OPOs) is attracting an increasing interest. The interest stems from two viewpoints: (1) from the fundamental physical viewpoint, since the nonlinear optical systems are convenient systems for studies of self-organization and pattern formation in spatially extended systems; (2) from the viewpoint of applications, since optical patterns have an application potential for parallel information processing, for image processing, nonlinear microscopy, and related topics. Pattern formation in nonlinear mini-cavities is especially attractive from the application viewpoint due to the compactness of the system.

Transverse patterns have been predicted to occur and have been observed in several different nonlinear optical systems (see e.g. [1,2] for a review). In the case of a quadratic nonlinear interaction patterns have been predicted in OPOs [3-5], in degenerate OPOs [6,7], and in second harmonic generation SHG [8-10]. Degenerate OPOs are particularly interesting due to the possibility of excitation of phase patterns [11,12], and of phase solitons [13]. Experimentally transverse pat- terns have been observed for OPOs [14-16] and for second harmonic generation [17]. No patterns have been yet seen for degenerate OPOs, or for OPOs in monolithic micro- or mini-cavities.

Most of the theoretical-numerical studies on transverse patterns in nonlinear optics consider mean field approximation, which means equivalently a single longitudinal mode assumption. Within this assumption the emission of a spatially extended system evolves on a resonant ring in the far field domain with the ring radius dependent on the detuning on the resonator: $k_{\perp}^{2}=2|\mathbf{k}|\left(\omega-\omega_{0}\right) / c$, where $k_{\perp}$ is the transverse wave-number of the emitted radiation, $|\mathbf{k}|=\omega / c, \omega$ is the gain frequency (atomic gain frequency in lasers, half-pump-frequency for degenerate OPOs, and the frequency of injection in passive systems), $\omega_{0}$ is the eigenfrequency of the (closest) longitudinal mode of the resonator, and $c$ is the velocity of light in material. Therefore the off-axis (conical) emission with the cone angle depending on the detuning is a "weakly nonlinear" precursor of the nonlinear transverse patterns. The basic mechanism of the "essentially nonlinear" pattern formation in lasers is the tilted wave selection, i.e. a selection of one or several waves from those allowed by the above resonant ring condition [18]. Analogously the basic mechanism of the "essentially nonlin- 
ear" pattern formation in degenerate OPOs is the stripe pattern selection with the spatial Fourier components lying on the resonant ring [3-7].

Simple geometrical interpretation of the conical emission is that if the modulus of the wave-vector of the generated radiation $\mathbf{k}$ is larger than that of the resonant one $|\mathbf{k}|>k_{n}\left(k_{n}=2 \pi n / L\right.$ is the wave-number corresponding to the nearest longitudinal mode of the resonator of length $L$ ), then the radiation is emitted at some angle in order to match the resonance condition: $k_{\perp}^{2}=|\mathbf{k}|^{2}-k_{n}^{2}$. Assuming, however, that several longitudinal modes can be excited with $k_{n-j}=$ $2 \pi(n-j) / L, j=0,1,2, \ldots$, the multi-conical emission can be expected, with $k_{\perp, j}^{2}=|\mathbf{k}|^{2}-k_{n-j}^{2}$. Despite this relatively simple geometrical interpretation of multi-conical emission no numerical simulation of multiconical transverse patterns has been reported to our knowledge. Theoretically the multi-conical emission for OPOs was predicted in [19]. Experimentally nonlinear multiconical patterns were never observed in OPOs, however were observed in a related system photorefractive scillators [20,21]. We report here the results of our study of multiconical emission of monolithical OPOs: (1) we present the results of numerical study based on numerical integration of OPO equations without using the mean field approximation; (2) we give the experimental evidence of multiconical emission; (3) we show experimentally and interpret theoretically the tunability of the angles of the conical and multiconical emission.

\section{Theory}

Our theoretical study is based on the non-mean-field model of a degenerate OPO, introduced e. g. in [22]:

$$
\begin{aligned}
\left(\frac{\partial}{\partial z}+\frac{1}{c} \frac{\partial}{\partial t}\right) A_{1} & =-\mathrm{i} \frac{\Delta k}{2}+\sigma A_{0} A_{1}^{*} \\
& +\mathrm{i} d_{1} \nabla_{\perp}^{2} A_{1} \\
\left(\frac{\partial}{\partial z}+\frac{1}{c} \frac{\partial}{\partial t}\right) A_{0} & =-\frac{\sigma}{2} A_{1}^{2}+\mathrm{i} d_{0} \nabla_{\perp}^{2} A_{0}
\end{aligned}
$$

for the slowly varying complex envelopes of the subharmonic $A_{1}(x, y, z, t)$ and pump $A_{0}(x, y, z, t)$ waves propagating along the longitudinal direction $z$, and diffracting in the transverse space: $\nabla_{\perp}^{2}=\left(\partial^{2} / \partial x^{2}+\right.$ $\left.\partial^{2} / \partial y^{2}\right)$ with the diffraction coefficients $d_{i}=1 /\left(2 k_{i}\right)$. The phase mismatch $\Delta k$ in the present study is set to zero, assuming a phase matched interaction for sim- plicity. Equations (1) are coupled with the boundary conditions:

$$
\begin{aligned}
& A_{1}(x, y, z=0, t) \\
& =A_{1}(x, y, z=L, t) \cdot r \cdot \mathrm{e}^{\mathrm{i} \Delta \varphi}, \\
& A_{1}(x, y, z=0, t)=E,
\end{aligned}
$$

where $r$ is the reflectivity of the output mirror (assuming $100 \%$ reflectivity for subharmonics of input mirror), $L$ is the full resonator length, $\Delta \varphi=k L$ is the phase mismatch over the resonator roundtrip, and $E$ is the intensity of the pump wave entering into the resonator. The boundary condition Eq. (2a) means, that subharmonic field $A_{1}(x, y, z, t)$ reflects from the input mirror instantaneously (with no delay).

We integrated Eq. (1) using a split step technique, i. e. integrating the nonlinear part in the space domain and the diffractive part in the spatial wavevector (Fourier) domain on a grid of $\left(n_{x}, n_{y}, n_{z}\right)=$ $(256,256,128)$. Typical numerical results are shown in Fig. 1. Two stages of the evolution of spatial patterns can be distinguished:

1. A weakly nonlinear stage, characterized by formation of multiple ring structure in the far field, with the radius of the inner ring depending on the detuning of the resonator $\Delta \varphi=k L$ (see Fig. 1(a,b) illustrating the patterns for different values of the detuning). The near field (intensity as well as the phase) looks completely irregular at that stage.

2. An essentially nonlinear stage, characterized by a further selection of radiation modes belonging to the different, as well as on the same, resonant rings. The nonlinear patterns are very different for different detunings. For small detuning the zigzagged phase domains can appear, where zigzagging is due to coexistence of the radiation on two different resonant rings (different space scales), Fig. 1(c). For moderate detuning the locking between spatial field harmonics on different resonant rings can occur, leading e.g. to stripes with pronounced high harmonics (flat top stripes), Fig. 1(d). At some values of detunings a competition between the different resonant rings can occur, leading to spatial separation of radiation on different longitudinal modes, Fig. 1(e). In the latter case the patterns with two different spatial scales are clearly visible. Apart from above listed patterns, which are typical for multi-longitudinalmode case, the patterns analogous to those predicted by mean field theories are also observed. 

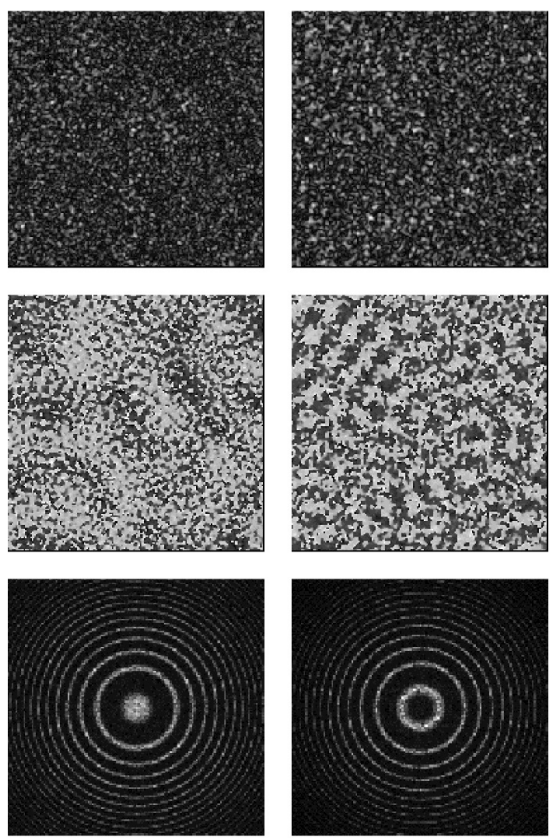

(a)

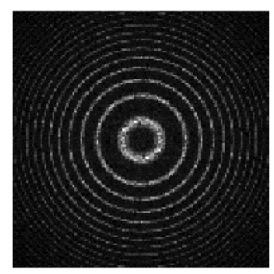

(b)
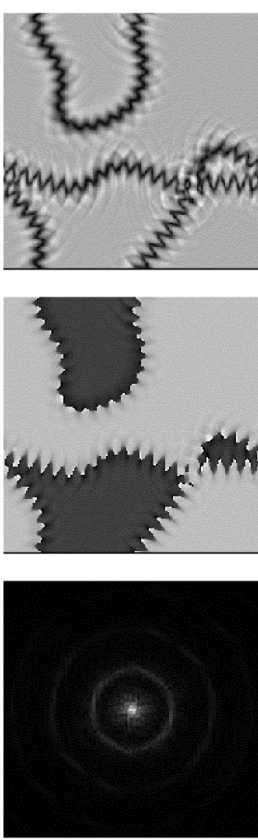

(c)
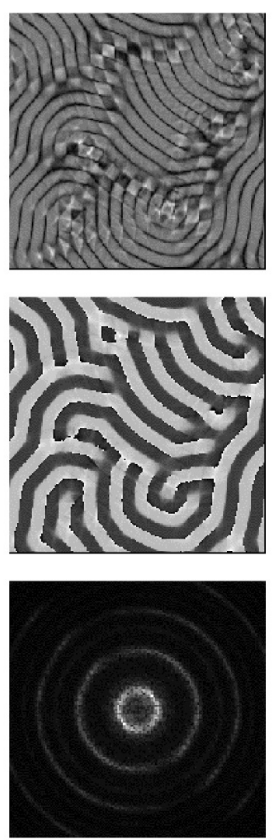

(d)
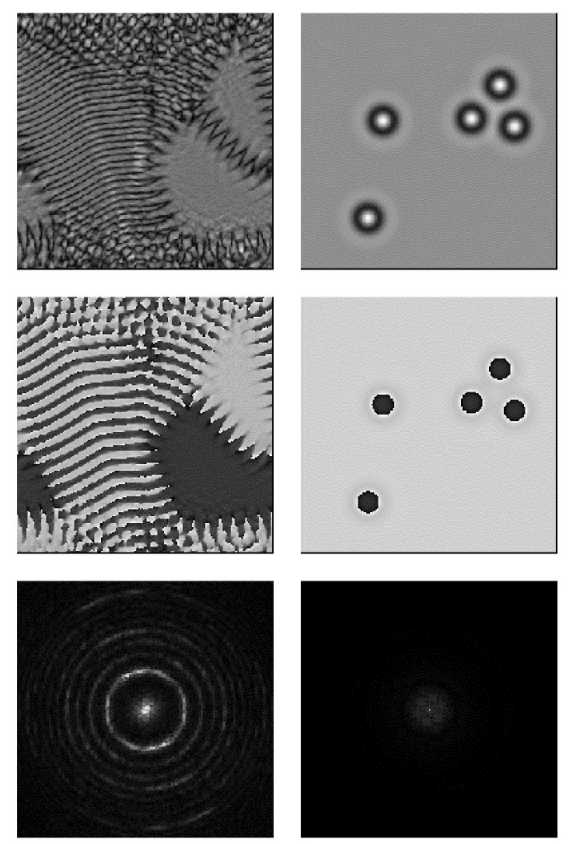

(e)

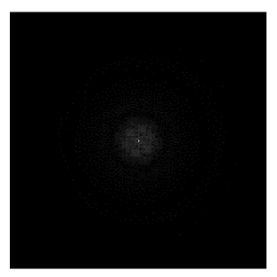

(f)

Fig. 1. Transverse patterns in multi-longitudinal-mode OPOs, as obtained by numerical integration of Eq. (1). Intensity distributions of subharmonic field (near field) at the top, phase of the field (grayness corresponds to phase ranging from 0 to $2 \pi$ ) in the middle, and intensity distribution in spatial Fourier domain (far field) at the bottom. Parameters used in integration: total losses of the resonator: $r=0.95$ (resonator finesse $Q=62$ ), unsaturated gain per resonator roundtrip: $\sigma E L=0.5$, Fresnel number of the resonator for subharmonics: $f^{2}=a^{2} /(\lambda L)=a^{2} /\left(4 \pi d_{1} L\right)=400$ ( $a$ is the transverse size of integration window with periodic boundary conditions). Integration is performed on the grid $256 \times 256$ in transverse space and 128 in longitudinal direction. Cases (a) and (b) correspond to the linear stage of pattern evolution with the number of roundtrips $n_{\text {roundtrip }}=10$, and cases (c), (d), (e), and (f) to the nonlinear stage with $n_{\text {roundtrip }}=200$.

Cavity detuning: (a) and (c) $\Delta \varphi=0$, (b) and (d) $\Delta \varphi=0.75$, (e) $\Delta \varphi=3$, and (f) $\Delta \varphi=0.3$.

Figure 1(f) is one such example: it shows phase (or dark ring) solitons, Fig. 1(e), whose analogs have been found in mean field approximation [13].

We presented here an unsystematic description of transverse patterns of multi-longitudinal-mode OPOs in order to give a taste of the complexity of transverse (multiconical) patterns in OPOs. A detailed theoretical and numerical investigation of the essentially nonlinear multi-longitudinal-mode transverse patterns will be presented elsewhere. Here we concentrate on the very fact of multi-ring transverse patterns and present first experimental evinces of such patterns.

\section{Experiment and interpretation}

The experiments used a BBO type I crystal of size $5 \times 5 \times 1.7 \mathrm{~mm}^{3}$, with the $1.7 \mathrm{~mm}$ thickness along the propagation direction. The phase matching direction for degenerate parametric down conversion at $532 \mathrm{~nm}$ is coincident with the optical axis of the cavity. Hightransmission coatings for $532 \mathrm{~nm}$ and high-reflection coatings for $1064 \mathrm{~nm}$ were used, resulting in a monolithic mini-cavity for subharmonic radiation. High 94\% reflectivity at $1064 \mathrm{~nm}$ results in finesse of the cavity $Q=50$.

The experimental scheme is shown in Fig. 2(a). The pump source is a Nd:YAG passively modulated laser, generating $1064 \mathrm{~nm}$ pulses of $13 \mathrm{~ns}$ duration, $5 \mathrm{~mJ}$ energy and TEM $_{00}$ spatial mode. After the Nd:YAG amplifier system and second harmonic generator (SHG) we have $532 \mathrm{~nm} \mathrm{5-12} \mathrm{mJ} \mathrm{pulses} \mathrm{for} \mathrm{pumping} \mathrm{the} \mathrm{OPO.}$ In the case of a $13 \mathrm{~ns}$ pulse duration around 1000 resonant wave cavity round trips are possible in a $1.7 \mathrm{~mm}$ long BBO resonator. Q-switching of the pump laser leads to emission with a small number of longitudinal modes (usually a single or two neighbouring longitudinal modes are emitted). The mini-cavity orientation with respect to the pump beam can be changed in both directions. After passing the mini-cavity the pump beam is filtered out.

First we measured the main resonator characteristics of the mini-cavity. We explored the transmission of the cold resonator by illuminating it with radiation at the sub-harmonic at $\lambda=1064 \mathrm{~nm}$ in the absence of a pump beam. Transmission resonances were observed at some angles as shown in Fig. 2(b). An additional variation of 


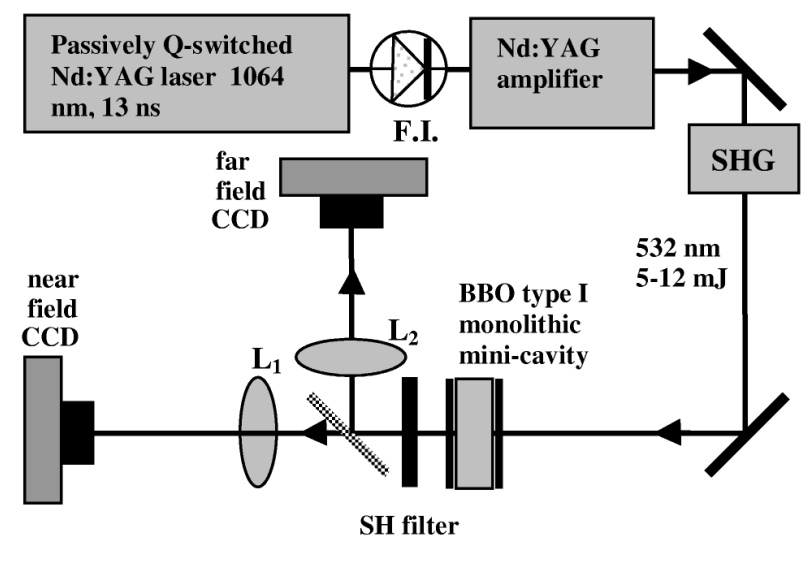

(a)

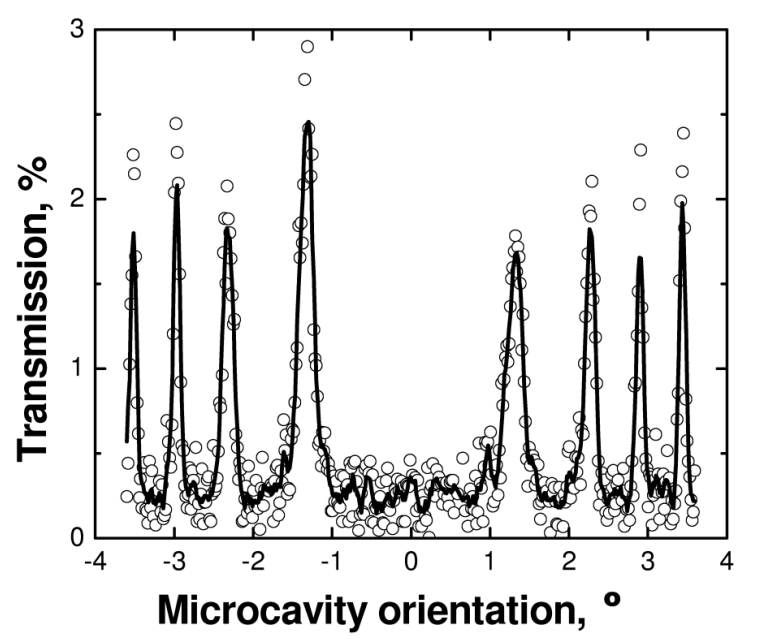

(b)

Fig. 2. (a) Experimental scheme: F. I. is Faraday isolator, $\mathrm{L} 1$ is $2 \mathrm{f}-2 \mathrm{f}$ near field imaging lens, $\mathrm{L} 2 \mathrm{is} \mathrm{f}-\mathrm{f}$ far field imaging lens. (b) Resonances of the cold cavity for $1064 \mathrm{~nm}$ : an experimentally recorded transmission coefficient depending on a tilt of the cavity in one (of two possible) direction.

the detuning (the cavity length) is possible by changing the temperature of the monolithic mini-cavity, resulting in variation of the radii of the concentric rings. A temperature change over $10{ }^{\circ} \mathrm{C}$ corresponds to the change of the full cavity length by one $\lambda$, i. e. allows tuning over a free spectral range of the mini-cavity transmission.

In the case of a monolithic BBO mini-cavity only a few parameters can be varied for achieving optical parametrical oscillation: (i) cavity face plate orientation with respect to the direction of the pump beam in both directions: along the phase matching direction and transversally to it; and (ii) cavity detuning through temperature induced crystal length change. In this experiment we kept the cavity temperature constant. The BBO monolithic mini-cavity was pumped with $532 \mathrm{~nm}$ pulses of $10 \mathrm{~mJ}$ energy. The pump beam diameter at the mini-cavity face plate was $2 \mathrm{~mm}$. OPO radiation was observed for mini-cavity optical axes oriented at small $0.5-1.2^{\circ}$ angles with respect to the pump beam in the phase matching direction. The lowest OPO threshold of $7 \mathrm{~mJ}$ pump beam intensity $\left(17 \mathrm{MW} / \mathrm{cm}^{2}\right)$ was observed for $0.75^{\circ}$ incidence angle.

Figure 3 shows a typical near field OPO emission pattern. First of all the quality of the monolithic crystal was not ideal: several defects, in bulk as well as on the surface, were present resulting in distorted near field distributions (white spot surrounded by concentric rings). These defects limit severely the ability to observe theoretically predicted patterns, however several signatures of theoretically predicted multi-

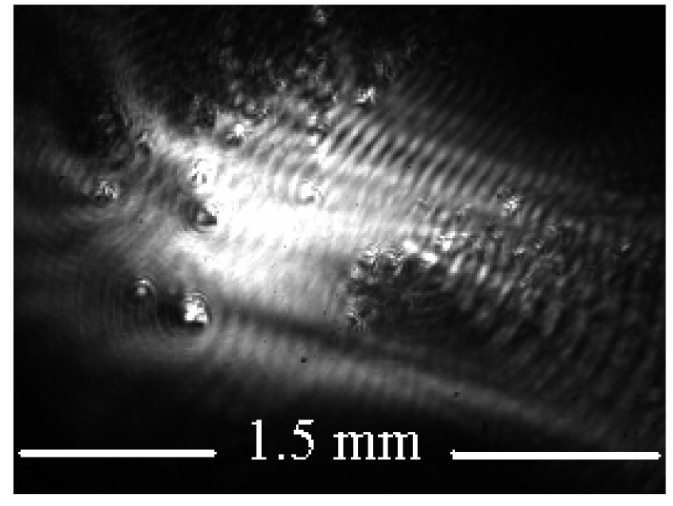

Fig. 3. Typical near field pattern of mini-cavity OPO emission.

longitudinal-mode patterns can be identified. The coexistence of stripes with different spatial scales is observed.

Figure 4 shows a typical far field OPO emission pattern. Signal and idler waves are always generated with a particular angle between them (conical emission). The pump beam direction is always between the signal and idler waves. In Fig. 4(e) a faint pattern of cold cavity rings can also be observed.

The directions of the signal and idler waves and the angle of conical emission depend strongly on the minicavity orientation with respect to the pump beam, as Fig. 4(a-d) shows. Figure 4(a) shows the generation on one resonant cone; Fig. 4(b) indicates that two cone emission is possible. This generation pattern is very sensitive to cavity orientation in the phase matching di- 


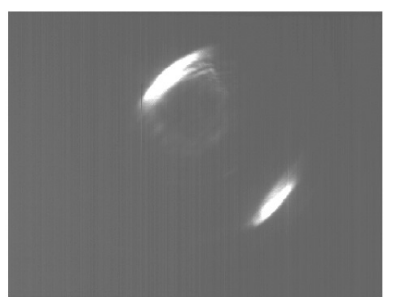

$\varphi=2.2^{\circ} \alpha_{x}=0.5^{\circ} \alpha_{y}=0.5^{\circ}$

(a)

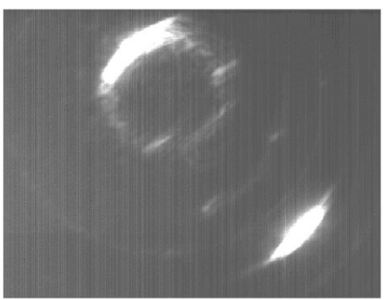

$\varphi=3.3^{\circ} \alpha_{x}=0.6^{\circ} \alpha_{y}=0.5^{\circ}$

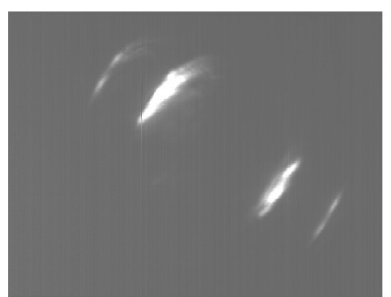

$\varphi=2.2 ; 3.3^{\circ} \alpha_{x}=\operatorname{0.68}^{\circ} \alpha_{y}=\operatorname{0.5}^{\circ} \varphi=3.3^{\circ} \alpha_{x}=0.75^{\circ} \alpha_{y}=0.5^{\circ}$

(b)

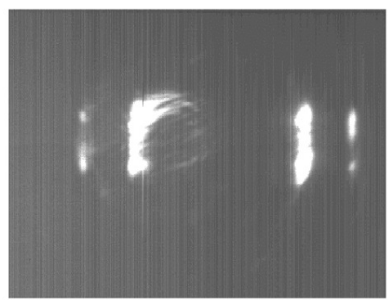

$\varphi=2.2 ; 3.3^{\circ} \alpha_{x}=0.6^{\circ} \alpha_{y}=0^{\circ}$

(f)

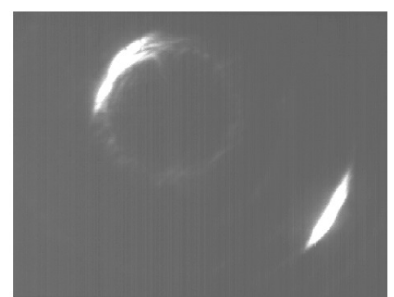

(c)

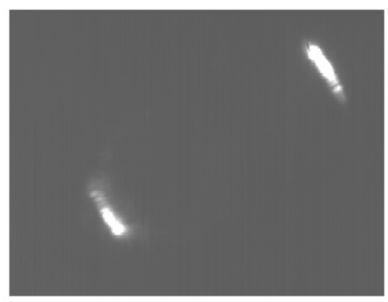

$\varphi=3.3^{\circ} \alpha_{x}=0.6^{\circ} \alpha_{y}=-0.4^{\circ}$

(g)

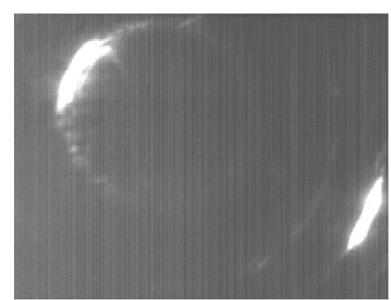

$\varphi=4.1^{0} \alpha_{x}=0.9^{\circ} \alpha_{y}=0.5^{\circ}$

(d)

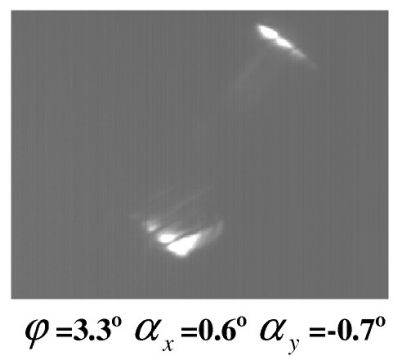

(h)

Fig. 4. Experimentally recorded far field pattern of DOPO. (a)-(d) mini-cavity orientation as the pump beam is tilted in the phase-matching direction $\alpha_{x},(\mathrm{e})-(\mathrm{h})$ - in the non phase-matching direction $\alpha_{y}$.

rection, and is very weakly dependent on the pump energy, which indicates that the regime is quasi-linear.

When the mini-cavity orientation is changed in the non phase matching direction, the signal and idler waves rotate around the direction of the pump beam, Fig. 4(e-h). Here the mini-cavity orientation angle in the phase matching direction is fixed at a $0.75^{\circ}$ angle. Our observations show that the signal and idler waves rotate around the pump beam direction by nearly $180^{\circ}$ when the orientation is changed by $\pm 1^{\circ}$. The OPO threshold increases when the mini-cavity orientation in the non phase matching direction exceeds $0.5^{\circ}$. At the value of $1^{\circ}$ the OPO threshold energy rises from $7 \mathrm{~mJ}$ to $15 \mathrm{~mJ}$ (intensity $36 \mathrm{MW} / \mathrm{cm}^{2}$ ).

The interpretation of the observed rotation of conical and multiconical patterns follows from the detailed inspection of the multiconical OPO emission model described above. Figure 5 illustrates the interpretation, where the white spot indicates the direction of the pump beam tilted with respect to the optical axis of the resonator. The generated pattern combines several conditions:

1. Resonance conditions for the mini-resonators (multicones with respect to the optical axis of the resonator) as obtained by the numerical analysis of Eqs. (1) and (2), which means that the emission should reside on the resonant rings.

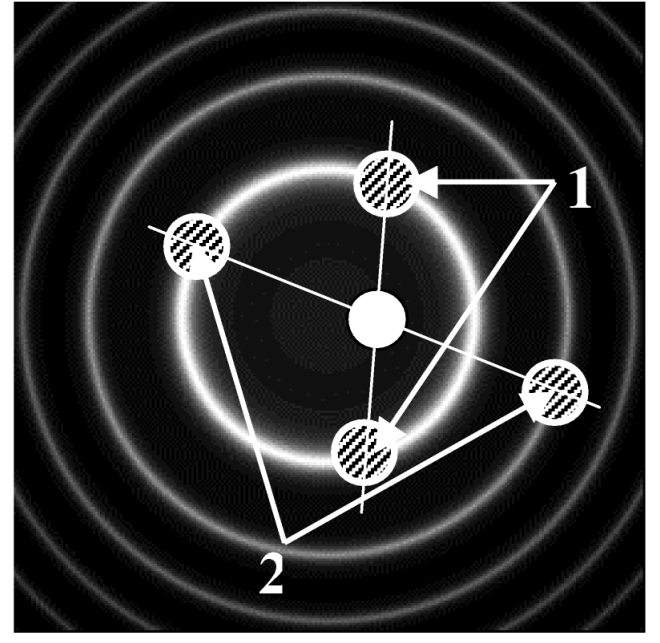

Fig. 5. Ring structure of the radiation in a cold cavity. The white spot indicates direction of the pump beam, and the pairs of symmetrically (with respect to the pump direction) placed pattern spots illustrate possible directions of the OPO generation. The pair 1 illustrates possible OPO generation on the same (first) ring, the pair 2 - on two different rings. The tilting of the micro-resonator orientation with respect to pump direction corresponds to a shift of the white spot in figure, and evidently results in complicated change of the character of radiation in the far field.

2. Momentum conservation condition, which means that the emission in the far field domain must be symmetric with respect to the direction of the pump. 
3. Phase matching condition, which means that the maximum parametric amplification is on a phase matching cone with the angle depending on the tilt of the cavity in the "phase matching direction".

The patterned spots, as shown in Fig. 5, indicate the possible direction of OPO generation. It is obvious from this illustration that the fulfillment of the above conditions results in a complicated angular structure of the OPO generation.

\section{Conclusions}

In conclusion, we demonstrated OPO generation in a monolithic BBO type I crystal mini-cavity. We show that OPO emission in a monolithic mini-cavity is conical and multiconical, so signal and idler wave directions depend on cavity detuning to laser frequency, phase matching cone and cavity orientation with respect to the pump beam. This allows the OPO emission direction to be controlled by changing the minicavity orientation, by temperature changes, or by laser frequency change. In the case of external monolithic mini-cavity refractive index change, or external phase matching condition change, the OPO emission angles can be modulated or attenuated (external electric field or external light induced refractive index change).

We expect that OPO far field control is also possible for a non-monolithic cavity, although the monolithic mini-cavity is attractive for compactness and stability of the cavity alignment.

\section{Acknowledgements}

Financial support from NATO Linkage Grant PST. CGL. 979050 and Lithuanian State Science and Studies Foundation is acknowledged. M. S. was supported by National Science Foundation grant ECS-0200372, and K. S. by project FIS2004-02587 of the Spanish Ministry of Science and Technology.

\section{References}

[1] L.A. Lugiato, M. Brambilla, and A. Gatti, in: Advances in Atomic, Molecular and Optical Physics 440, eds. B. Bederson and H. Walther (Academic Press, 1998) pp. 229-306, and references quoted therein.

[2] K. Staliunas and V.J. Sanchez-Morcillo, Transverse Patterns in Nonlinear Optical Resonator, Springer Tracts in Modern Physics 183 (Springer, Berlin 2003).

[3] K. Staliunas, Optical vortices during three-wave nonlinear coupling, Opt. Commun. 91(1-2), 82-86(1992).
[4] G.-L. Oppo, M. Brambilla, D. Camesasca, A. Gatti, and L.A. Lugiato, Spatiotemporal dynamics of optical parametric oscillators, J. Mod. Opt. 41(6), 1151-1162 (1994).

[5] S. Longhi and A. Geraci, Swift-Hohenberg equation for optical parametric oscillators, Phys. Rev. A 54(5), 4581-4584 (1996).

[6] K. Staliunas, Transverse pattern formation in optical parametric oscillators, J. Mod. Opt. 42(6), 1261-1269 (1995).

[7] G.J. de Valcárcel, K. Staliunas, E. Roldán, and V.J. Sánchez-Morcillo, Transverse patterns in degenerate optical parametric oscillation and degenerate fourwave mixing, Phys. Rev. A 54(2), 1609-1624 (1996).

[8] C. Etrich, U. Peschel, and F. Lederer, Solitary waves in quadratically nonlinear resonators, Phys. Rev. Lett. 79(13), 2454-2457 (1997).

[9] C. Etrich, U. Peschel, and F. Lederer, Pattern formation in intracavity second-harmonic generation, Phys. Rev. E 56(4), 4803-4808 (1997).

[10] P. Lodahl and M. Saffman, Pattern formation in singly resonant second-harmonic generation with competing parametric oscillation, Phys. Rev. A 60(4), 3251-3261 (1999).

[11] S. Trillo, M. Haelterman, and A. Sheppard, Stable topological spatial solitons in optical parametric oscillators, Opt. Lett. 22(13), 970-972 (1997).

[12] K. Staliunas and V.J. Sanchez-Morcillo, Dynamics of domains in Swift-Hohenberg equation, Phys. Lett. A 241(1-2), 28-34 (1998).

[13] K. Staliunas and V.J. Sanchez-Morcillo, Spatial localized structures in degenerate optical parametric oscillators, Phys. Rev. A 57(2), 1454-1457 (1998).

[14] V. Sirutkaitis, R. Grigonis, G. Slekys, and K. Staliunas, Spatial structures in synchronously pumped optical parametric oscillators, Quantum Semicl. Opt. 1(1), 139-145 (1999).

[15] M. Vaupel, A. Maître, and C. Fabre, Observation of pattern formation in optical parametric oscillators, Phys. Rev. Lett. 83(25), 5278-5281 (1999).

[16] S. Ducci, N. Treps, A. Maître, and C. Fabre, Pattern formation in optical parametric oscillators, Phys. Rev. A 64(2), 023803 (2001) [6 pages].

[17] A.V. Mamaev, P. Lodahl, and M. Saffman, Observation of spatial modulation instability in intracavity secondharmonic generation, Opt. Lett. 28(1), 31-33 (2003).

[18] P.K. Jakobsen, J.V. Moloney, A.C. Newell, and R. Indik, Space-time dynamics of wide-gain-section lasers, Phys. Rev. A 45(11), 8129-8137 (1992).

[19] S. Longhi, Spatio-temporal instabilities and threshold condition in a broad-area optical parametric oscillator, Opt. Commun. 153(1-3), 90-94 (1998).

[20] A.V. Mamaev and M. Saffman, Pattern formation in a linear photorefractive oscillator, Opt. Commun. 128(4-6), 281-286 (1996). 
[21] K. Staliunas, V.B. Taranenko, G. Slekys, R. Viselga, and C.O. Weiss, Dynamical spatial localized structures in lasers with intracavity saturable absorbers, Phys. Rev. A 57(1), 599-604 (1998).
[22] S. Longhi, Hydrodynamic equation model for degenerate optical parametric oscillators, J. Mod. Opt. 43(6), 1089-1094 (1996).

\title{
DAUGIAKŪGIAI SKERSINIAI ŠVIESOS DARINIAI MONOLITINIAME PARAMETRINIAME ŠVIESOS MINIGENERATORIUJE
}

\author{
M. Peckus ${ }^{\text {a }}$, K. Staliūnas ${ }^{\text {b }}$, M. Saffman ${ }^{\text {c }}$, G. Šlekys ${ }^{d}$, V. Sirutkaitis ${ }^{a}$, V. Smilgevičius ${ }^{\text {a }}$, R. Grigonis ${ }^{\text {a }}$ \\ ${ }^{a}$ Vilniaus universitetas, Vilnius, Lietuva \\ ${ }^{\mathrm{b}}$ Katalonijos politechnikos universitetas, Barselona, Ispanija \\ ${ }^{\mathrm{c}}$ Viskonsino universitetas, Medisonas, JAV \\ ${ }^{\mathrm{d}}$ Altechna, Vilnius, Lietuva
}

\section{Santrauka}

Skersinių šviesos darinių susidarymas netiesinèse optinėse sistemose, kaip antai didelès apertūros lazeriuose, fotorefrakciniuose osciliatoriuose, parametriniuose šviesos generatoriuose, sulaukia vis didesnio susidomèjimo. Fundamentinès fizikos požiūriu tokios sistemos yra patogios studijuoti saviveiką ir skersinių darinių susidarymą, o praktikoje jas galima naudoti lygiagrečiam informacijos apdorojimui, netiesinèje mikroskopijoje ir pan. Skersinius šviesos darinius tirti monolitiniuose minirezonatoriuose patogu ir dèl sistemos kompaktiškumo.

Optinėse terpèse su kvadratiniu netiesiškumu skersinių šviesos darinių radimasis jau yra numatytas vykstant parametrinei šviesos generacijai (tiek išsigimusiai, tiek ir neišsigimusiai) ir antros harmonikos generacijai. Išsigimęs parametrinis šviesos generatorius idomus dar ir tuo, kad jame teoriškai numatomas faziniu domenu ir fazinių solitonų susidarymas. Eksperimentiškai skersinių šviesos darinių susidarymas buvo pastebètas, vykstant neišsigimusiai parametrinei šviesos generacijai ir antros harmonikos generacijai. Kiek mums žinoma, skersinių šviesos darinių susidarymas monolitiniuose mikrorezonatoriuose ar minirezonatoriuose dar nebuvo stebètas.

Pateikti daugiakūgès optinès parametrinès šviesos generacijos tyrimo monolitiniame minirezonatoriuje rezultatai: 1) skaitmeninių tyrimu rezultatai integruojant parametrinio osciliatoriaus lygtis nenaudojant vidurkinto lauko artinio; 2) eksperimentiškai pastebèti skersiniai šviesos dariniai atitinkamame rezonatoriuje; 3) praktiškai pademonstruota ir teoriškai paaiškinta daugiakūgès generacijos kampo ir krypties priklausomybè nuo minirezonatoriaus ilgio ir kaupinimo krypties. 